NASA/TM-2004-212906

\title{
Mean Flow and Noise Prediction for a Separate Flow Jet With Chevron Mixers
}

L. Danielle Koch and James Bridges

Glenn Research Center, Cleveland, Ohio

Abbas Khavaran

QSS Group, Inc., Cleveland, Ohio 
Since its founding, NASA has been dedicated to the advancement of aeronautics and space science. The NASA Scientific and Technical Information (STI) Program Office plays a key part in helping NASA maintain this important role.

The NASA STI Program Office is operated by Langley Research Center, the Lead Center for NASA's scientific and technical information. The NASA STI Program Office provides access to the NASA STI Database, the largest collection of aeronautical and space science STI in the world. The Program Office is also NASA's institutional mechanism for disseminating the results of its research and development activities. These results are published by NASA in the NASA STI Report Series, which includes the following report types:

- $\quad$ TECHNICAL PUBLICATION. Reports of completed research or a major significant phase of research that present the results of NASA programs and include extensive data or theoretical analysis. Includes compilations of significant scientific and technical data and information deemed to be of continuing reference value. NASA's counterpart of peerreviewed formal professional papers but has less stringent limitations on manuscript length and extent of graphic presentations.

- TECHNICAL MEMORANDUM. Scientific and technical findings that are preliminary or of specialized interest, e.g., quick release reports, working papers, and bibliographies that contain minimal annotation. Does not contain extensive analysis.

- CONTRACTOR REPORT. Scientific and technical findings by NASA-sponsored contractors and grantees.
- CONFERENCE PUBLICATION. Collected papers from scientific and technical conferences, symposia, seminars, or other meetings sponsored or cosponsored by NASA.

- SPECIAL PUBLICATION. Scientific, technical, or historical information from NASA programs, projects, and missions, often concerned with subjects having substantial public interest.

- TECHNICAL TRANSLATION. Englishlanguage translations of foreign scientific and technical material pertinent to NASA's mission.

Specialized services that complement the STI Program Office's diverse offerings include creating custom thesauri, building customized databases, organizing and publishing research results ... even providing videos.

For more information about the NASA STI Program Office, see the following:

- Access the NASA STI Program Home Page at http://www.sti.nasa.gov

- E-mail your question via the Internet to help@sti.nasa.gov

- Fax your question to the NASA Access Help Desk at 301-621-0134

- Telephone the NASA Access Help Desk at 301-621-0390

- Write to:

NASA Access Help Desk

NASA Center for AeroSpace Information 7121 Standard Drive

Hanover, MD 21076 
NASA/TM-2004-212906

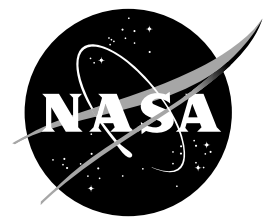

\section{Mean Flow and Noise Prediction for a Separate Flow Jet With Chevron Mixers}

L. Danielle Koch and James Bridges

Glenn Research Center, Cleveland, Ohio

Abbas Khavaran

QSS Group, Inc., Cleveland, Ohio

Prepared for the

42nd Aerospace Sciences Meeting and Exhibit

sponsored by the American Institute of Aeronautics and Astronautics

Reno, Nevada, January 5-8, 2004

National Aeronautics and

Space Administration

Glenn Research Center 


\section{Acknowledgments}

L. Danielle Koch would like to express her gratitude to Dr. Nicholas Georgiadis and Dennis Yoder for their guidance in obtaining the WIND mean flow solution, and to Dr. Christopher Miller for his assistance with parallel processing issues.

Available from

NASA Center for Aerospace Information 7121 Standard Drive

Hanover, MD 21076
National Technical Information Service 5285 Port Royal Road Springfield, VA 22100

Available electronically at http:/ /gltrs.grc.nasa.gov 


\title{
MEAN FLOW AND NOISE PREDICTION FOR A SEPARATE FLOW JET WITH CHEVRON MIXERS
}

\author{
L. Danielle Koch ${ }^{*}$ and James Bridges ${ }^{*}$ \\ National Aeronautics and Space Administration \\ Glenn Research Center \\ Cleveland, Ohio 44135 \\ Abbas Khavaran ${ }^{*}$ \\ QSS Group, Inc. \\ Cleveland, Ohio 44135
}

\begin{abstract}
$\underline{\text { ABSTRACT }}$
Experimental and numerical results are presented here for a separate flow nozzle employing chevrons arranged in an alternating pattern on the core nozzle. Comparisons of these results demonstrate that the combination of the WIND/MGBK suite of codes can predict the noise reduction trends measured between separate flow jets with and without chevrons on the core nozzle. Mean flow predictions were validated against Particle Image Velocimetry (PIV), pressure, and temperature data, and noise predictions were validated against acoustic measurements recorded in the NASA Glenn Aeroacoustic Propulsion Lab. Comparisons are also made to results from the CRAFT code. The work presented here is part of an on-going assessment of the WIND/MGBK suite for use in designing the next generation of quiet nozzles for turbofan engines.
\end{abstract}

\section{INTRODUCTION}

One of the most promising techniques to reduce the noise from modern turbofan engines is to enhance mixing of the core and fan jet streams by serrating the edges of the jet nozzles. Chevrons, as these serrations will be referred to in this paper, are an attractive technique for reducing jet noise since they are a mechanically simple modification to current engine nozzle designs and have been proven to be able to reduce noise with small thrust penalties. However, in order to optimize the design of these chevrons, more must be known about how they change the jet mixing and how this improved mixing results in lower noise. World-class experimental and numerical studies of turbulent jets are currently underway at the NASA Glenn Research center to both further our understanding of aeroacoustic noise and to develop computer codes that will allow engineers to design the next generation of quiet nozzles.

${ }^{*}$ Senior Member AIAA.
Computational design tools that would allow engineers to parametrically evaluate new low noise nozzle concepts are in great demand. Ideally, those design tools should quickly provide accurate aerodynamic and acoustic predictions for a wide variety of complicated three-dimensional nozzle geometries operating through a range of flow conditions. While acoustic predictions based on Reynolds-averaged Navier Stokes (RANS) solutions show promise of evolving from pure analysis tools to viable design tools, key issues must still be addressed through careful verification, validation, and automation efforts. Those issues include, but are not limited to, turbulence modeling, noise source modeling, and grid generation. Researchers at NASA Glenn are currently studying those issues experimentally in the Aeroacoustic Propulsion Laboratory (AAPL) and numerically with the WIND/MGBK suite of codes.

Several new comparisons are made in this report to augment previously published findings. New mean flow predictions generated at NASA Glenn using the WIND code are compared to previously reported results from Kenzakowski et al. using the CRAFT code (Ref. 1). Both predictions are now validated against PIV data collected in the summer of 2000. The PIV techniques were used for the first time to collect detailed velocity maps of the jet plumes, making turbulence data available for validation of numerical results (Refs. 2, 3). The PIV data augments the pressure and temperature data collected earlier for the same configurations (Ref. 1).

Acoustic predictions from the MGBK code using the WIND and CRAFT mean flow solutions are also presented in this report. The acoustic predictions are likewise compared to experimental measurements obtained in tests conducted in the AAPL. Comparisons are made that demonstrate the ability of the WIND/MGBK suite to predict trends in jet noise reduction. 


\section{AERODYNAMIC ANALYSIS}

\section{Experimental Details}

Experimental and numerical results are shown here for one separate flow nozzle employing chevrons on the core nozzle. That nozzle, designated $3 \mathrm{~A}_{12} \mathrm{~B}$ and seen in Figure 1, had 12 chevrons arranged in an alternating pattern - into and out of the core flow.

PIV flow field data was acquired for the $3 \mathrm{~A}_{12} \mathrm{~B}$ model in the AAPL at NASA Glenn Research Center. Within the acoustically lined confines dome of the AAPL was the Nozzle Acoustic Test Rig (NATR), a free-jet, forward-flight-simulation test rig. The test nozzle models were installed on the aft end of the hydrogen-fired jet exit rig (JER) that was located at the exit of the NATR duct. The core stream of the rig was used to provide the hot core flow, while the fan flow came from a secondary strut into a dual flow 'pod' fastened just aft of the combustor.

In these tests, the core and bypass streams were seeded with aluminum oxide $\left(\mathrm{Al}_{2} \mathrm{O}_{3}\right)$ powder using two identical, specially built, fluidized bed seeders. The alumina powder had a specific gravity of 3.96; the particle size distribution had a mean of $0.7 \mu \mathrm{m}$ and a standard deviation of $0.2 \mu \mathrm{m}$. The seeders provided roughly 0.5 liters/hour of dry seed particles each, seeding the flow at a density of $\sim 10$ particles $/ \mathrm{mm}^{3}$. Given the light sheet thickness of $0.2 \mathrm{~mm}$, this produces on the order of 10 particles in a $2 \mathrm{~mm}$ by $2 \mathrm{~mm}$ interrogation region. The ambient flow was seeded by a commercial fogger, Vicount 5000, manufactured by Corona Technologies, Inc. This fogger produced droplets in the $0.2-0.3$ micron diameter range at a rate of 5 liters/hour of fluid.

The PIV system was a two-camera system configured to yield two image fields, one above another with a slight overlap. The two $1 \mathrm{~K} \times 1 \mathrm{~K}$ pixel Kodak ES 10 cameras equipped with f/5.6, $85 \mathrm{~mm}$ Nikkor lenses and $8 \mathrm{~mm}$ extension rings were arranged vertically 52 inches $(1.32 \mathrm{~m})$ away from the light sheet. The two cameras were positioned to overlap their fields of view by 0.5 inches, yielding a composite field of view 10.5 inches high by 5 inches wide $(0.267 \mathrm{~m} \times 0.127 \mathrm{~m})$. A dual head Nd:YAG laser operating at $532 \mathrm{~nm}$ was used to generate a $400 \mathrm{~mJ} /$ pulse light sheet. The laser, cameras, and all laser optics were mounted on a large axial traverse. Radial planes were measured in different circumferential angles by rotating the nozzle on the jet rig.

The collected PIV image data were processed using a NASA-developed code PIVPROC (Ref. 4). The correlation based processing allows subregion image shifting, asymmetric subregion sizes and multi-pass correlation processing. A grid was constructed, registered on the nozzle lip from the first frame image, so that velocities computed from each image would create a uniform map. Five velocity grid cells overlapped in the radial direction and three in the axial direction. A multipass scheme was employed, using first a 64 by 64 pixel region to determine mean shift of images, followed by a 32 by 32 pixel pass with $50 \%$ overlap between grid cells. The 32 by 32 pixel grid corresponded to a 0.088 inch $(2.24 \mathrm{~mm})$ grid size in physical space.

The procedure for computing statistics from a series of processed PIV image velocity vector maps utilized several acceptance criteria to qualify vectors and identify and remove incorrect vectors: signal to noise ratios for the image correlation, hard velocity cutoff limits and a Chauvenay criteria procedure for identifying outliers. A relative data 'quality' metric was defined as the number of accepted velocity vectors at a point relative to the total number of frame pairs processed. This field was used to blank out regions of the contour plots where the quality was less than 0.8 ; most regions had a quality metric in the $0.90-0.99$ range.

Subsequent to the acquisition of the PIV data it was determined that the model hardware was slightly asymmetric, with a droop of $1.5^{\circ}$ on the centerbody and roughly $1^{\circ}$ on the core nozzle. The data was acquired on the lower half of the plume. The ramification of this asymmetry are not fully known at this time, although it seems that the turbulence kinetic energy should have been somewhat lower than measured here. More documentation of this data set is provided in Reference 2.

\section{$\underline{\text { Computational Details }}$}

The mean flow solution for the $3 \mathrm{~A}_{12} \mathrm{~B}$ nozzle were generated at NASA Glenn using the WIND solver. WIND is a general-purpose code that solves the NavierStokes equations in a central-difference form. It was developed jointly by the NPARC Alliance and the Boeing Company. The CRAFT code, developed by Combustion Research and Flow Technology, Inc. is a finite-volume structured Navier-Stokes solver.

Both the CRAFT and WIND computations assumed that the turbulent Prandtl number was a constant value of 0.7 . The WIND solution used a viscous, two-equation Shear Stress Transport (SST) model (Ref. 5), while the CRAFT solution used a standard k-epsilon turbulence model. 
Uniform subsonic conditions were imposed at all inflow boundaries and are given in the table below.

\begin{tabular}{|l|l|}
\hline \multicolumn{2}{|c|}{ Fan Conditions } \\
\hline Total Pressure & $26.353 \mathrm{psia}$ \\
\hline Total Temperature & $600.00 \mathrm{R}$ \\
\hline \multicolumn{2}{|c|}{ Core Conditions } \\
\hline Total Pressure & $24.193 \mathrm{psia}$ \\
\hline Total Temperature & $1500.00 \mathrm{R}$ \\
\hline \multicolumn{2}{|c|}{ Freestream Conditions } \\
\hline Static Pressure & $14.40 \mathrm{psia}$ \\
\hline Static Temperature & $529.67 \mathrm{R}$ \\
\hline Mach Number & 0.28 \\
\hline
\end{tabular}

Both the WIND and CRAFT computations used structured grids that modeled a 30 degree circumferential segment of the nozzle, extending from the tip of the downward facing chevron to the tip of the upward facing chevron - that is, from one circumferential symmetry plane to the next, as shown in Figure 2.

While both the WIND and CRAFT calculations used parallel processing, different strategies were employed to further accelerate convergence. For the CRAFT computation, Kenzakowski, et al. utilized wall functions to reduce the overall size of the computational mesh, in addition to keeping the far field boundaries closer to the nozzle. For the NASA computation with the WIND code, grid sequencing was used to accelerate convergence on a larger mesh. The far field boundaries for the WIND computation extended approximately 13 fan nozzle diameters from the centerline and 32 fan nozzle diameters downstream of the fan nozzle exit plane.

Wall functions were not used for the WIND calculations, and the grid was accordingly packed towards the solid surfaces of the nozzle. The values of $\mathrm{y}+$ for the first gridline off the surfaces of the nozzle averaged less than 1. As a result, the WIND grid had approximately 11 million grid points while the CRAFT grid had a nearly 3 million grid points. The extents of the WIND and CRAFT grids for the $3 \mathrm{AB}$ nozzle are shown in Figure 3. All coordinates have been normalized by the fan nozzle diameter ( $D=9.621$ inches), and the axial datum is located at the fan nozzle exit plane.

The WIND solution was run on a 36 node LINUX cluster at NASA Glenn. The cluster consists of 11 nodes with $2.26 \mathrm{GHz}$ Pentium 4 processors (1024 MB of DDR266 SDRAM) and 25 nodes with $2.4 \mathrm{GHz}$ Pentium 4 processors (512 MB of PC1066 RDRAM).
All the nodes have gigabit ethernet built in to the motherboard. These nodes are connected in a private network via two 24 port managed gigabit switches trunked together using four ports on each switch. This cluster was used to run the parallel WIND code (Version 5.193) compiled for LINUX clusters to generate the mean flow prediction for the chevron nozzle.

Eleven processors were used to obtain the coarse and medium grid solutions from the WIND code, while the fine grid solution was run on 22 processors. Only the fine grid solutions will be presented in this paper. Further details concerning the CRAFT numerical techniques are given in Reference 1.

Convergence of the WIND solution was determined by the reduction in the L2 residual errors, as well as by the percentage differences between the centerline axial velocity and centerline turbulence kinetic energy distributions over a 1000 cycle sets. L2 norms were reduced by 4 orders of magnitude, while the change in centerline axial velocity was less than $0.1 \%$ and centerline turbulence kinetic energy was less than $1.5 \%$ (with the exception of the area in the immediate vicinity of the centerbody trailing edge).

Although the centerline values for axial velocity and turbulence kinetic energy prove to be convenient quantities to monitor a problem for convergence, changes in these quantities through the entire computational domain were examined, particularly in the shear layer regions. Turbulence kinetic energy was normalized by the square of the fan nozzle exit velocity and the percentage change over the last 1000 cycle set was examined. In the fan shear layer, the change in normalized turbulence kinetic energy was also less than $1.5 \%$. This examination gave additional quantitative evidence that the quantities that would be subsequently used for acoustic predictions using MGBK had reached steady state values throughout the domain, not just at the centerline.

$\underline{\text { Results }}$

Comparisons between the experimentally measured and calculated plume are shown in the contour plots of Figures 4 through 15 . The plots are grouped so that the reader can study both the axial and cross-sectional distributions of the plotted quantities by reading from left to right across both pages. Examining the WIND solution for example, Figure $4 \mathrm{c}$ shows the distribution of axial velocity taken at the symmetry plane passing through the downward facing chevron; Figure $5 \mathrm{c}$ shows the distribution of axial velocity taken at the symmetry plane passing through the upward facing chevron. On 
the next page, Figure $8 \mathrm{~b}$ shows a grouping of five cross-sectional distributions of the WIND axial velocity predictions. Those cross-sections are given at normalized axial locations of 1.091D, 1.871D, 3.118D, 6.236D and 10.394D. These locations correspond to the pressure and temperature rake locations. Note that the gaps appearing in the rendering of the CRAFT solution are a result of the mirroring of the cell-centered data. Gaps appearing in rendering of the data mask locations of faulty pressure and temperature probes. Also note that the circumferential datum for the data sets shown in Figures 8a, 9a, 14a, and 15a are clocked $30^{\circ}$ relative to the predictions.

Following the same grouping convention, Figures 6, 7, and 9 show the distributions of turbulence kinetic energy. Figures 10, 11 and 14 show the total pressure distributions. Figures 12, 13 and 15 show the total temperature distributions. All available experimental data is presented. Cross-sectional PIV data was not available for this nozzle, as was pressure and temperature rake data for the jet plume in the plane of the downward facing chevron.

Qualitatively, both Navier-Stokes codes appear to predict the magnitude and distributions of axial velocity, total pressure and total temperature reasonably well. The agreement between the experimental distribution of the turbulence kinetic energy and the values calculated by the WIND and CRAFT codes is not as close. There is a mismatch between the location and magnitude of the area of maximum turbulence kinetic energy.

Examining the measured and predicted distributions of turbulence kinetic energy in the plane of the upward canted chevron the CRAFT code predict that the value of maximum turbulence kinetic energy is approximately $17 \%$ lower than the measured value, and occurs approximately $14 \%$ farther downstream. The WIND code also underpredicted the turbulence kinetic energy, calculating the maximum value in this plane to be $17 \%$ lower than the measured value and approximately located 4\% farther downstream Similar underpredictions were reported for the base dual flow 3BB nozzle in Reference 6.

A comparison of the centerline axial velocities of the $3 \mathrm{~A}_{12} \mathrm{~B}$ nozzles with chevrons on the core nozzle with the $3 \mathrm{BB}$ baseline nozzle without chevrons is shown in Figure 16. The chevrons appeared to reduce the peak predicted axial velocity in the region between approximately 5 and 10 fan nozzle diameters downstream of the fan nozzle exit plane. Additional details about the 3BB nozzle are given in Reference 6 .
Mean flow computations are also valuable in providing qualitative information about the effectiveness of the chevrons. Figure 17 is one such examination, and displays an iso-surface of the axial component of vorticity near the chevron.

\section{ACOUSTIC ANALYSIS}

$\underline{\text { Experimental Details }}$

Far-field acoustic data was also acquired for the $3 \mathrm{~A}_{12} \mathrm{~B}$ model in the AAPL at NASA Glenn Research Center. During acoustic testing fiberglass wedge treatment of the dome made it anechoic down to $150 \mathrm{~Hz}$. Twenty-five $1 / 4$ in. B\&K microphones were placed on 10 foot poles on a nominally 50 foot arc were positioned every $5^{\circ}$ from $45^{\circ}$ (upstream) to $165^{\circ}$ to the inlet axis. All microphone signals were digitized simultaneously at $240 \mathrm{kHz}$ and processed in the narrowband domain using the Digital Acoustic Data Analysis (DADS) package. This processing includes background noise subtraction, and correction for microphone actuator response, free-field response, gridcap response, and atmospheric attenuation. It also includes a module to correct for the refraction and losses from the transmission of the sound through the freejet shear layer using the technique of Ahuja (Ref. 7), which is functionally equivalent to what is known in industry as Amiet's method.

\section{$\underline{\text { Computational Details }}$}

Far-field jet mixing noise from the underlying unsteady flow was predicted using averaged equations of motion, i.e., MGBK methodology (Ref. 8). The process involves two steps: modeling of noise sources of fine-scale turbulence, and refraction of sound through the shear flow to a far-field observer. The governing equation describing the source as well as refraction phenomena is the third-order wave operator known as Lilley's equation. This equation is linearized about a unidirectional transversely sheared base flow. The non-linear terms are moved to the right-hand side of the equation and identified as the source. Sources considered in the present predictions are the so-called self- and shear-noise terms in Lilley's terminology. Both are second-order in velocity fluctuations and are modeled using appropriate description of the statistical properties of turbulence.

As usual, a high-frequency Green's function derived for a locally parallel flow (Ref. 9) was used to account for refraction. The robustness of the predictions is mostly tied to this particular Green's function. A detailed examination of this solution and comparison 
with the ray-acoustic as well as exact Green's function (Ref. 10) shows that in the mid angle range it should remain accurate down to a Strouhal number $(S t=f D / U)$ of 0.50 .

Two-point space-time correlation of turbulent velocity components is modeled assuming an axisymmetric turbulence (Ref. 8). As such, the component ratio of turbulence and its length scales, i.e., $\left(u_{2}^{2} / u_{1}^{2}, \ell_{2} / \ell_{1}\right)$, in the radial and axial directions need to be specified at each source location within the turbulent jet. A pair of factors $(0.70,0.50)$ was used universally in the following predictions. In the special case of an isotropic turbulence both parameters are assumed as unity.

In general, sound spectral intensity scales as $k^{7 / 2}\left(\Omega \tau_{o}\right)^{4}$, where $\tau_{o}^{-1}$ is the source characteristic frequency, which is related to turbulence kinetic energy $k$ and its dissipation rate $\varepsilon$ as $\tau_{o}=2 k / \mathcal{E}$. The source frequency $\Omega$ is related to the observer frequency $\omega$ through the usual Doppler effect $\Omega=\left(1+M_{c} \cos \theta\right) \omega$, where $M_{c}$ is the source convection Mach number and observer angle, $\theta$, is measured from the jet inlet.

\section{$\underline{\text { Results }}$}

Two Navier-Stokes solutions provided by WIND and CRAFT were used as input to the MGBK code for noise prediction. Spectra and Overall Sound Pressure Level (OASPL) directivity were predicted on a $50 \mathrm{ft}$ arc (i.e., $R / D=62.5$ ) and compared with measurements. Comparisons account for the atmospheric attenuation at standard conditions. As seen in Figure 18, both Navier-Stokes solutions appear to predict similar results and compare reasonably well with data. The slight difference in the low frequency predictions results in a $0.70 \mathrm{~dB}$ difference in the OASPL directivity comparisons as seen in Figure 19. To investigate the potential success of WIND/MGBK suite as a design tool, the noise/data comparison for the base dual flow nozzle 3BB (Ref. 6) as well as the chevron nozzle in shown in Figure 20. All predictions were made with WIND input and using the same pair of anisotropy parameters defined earlier. The predicted trends appear consistent with data and exhibit a reduction in low frequency noise at the cost of an increase in high frequency noise due to enhanced mixing. The location of the crossover point in spectral shape from $3 \mathrm{BB}$ to $3 \mathrm{AB}$ configuration differs slightly between data and prediction.

\section{CONCLUSIONS AND RECOMMENDATIONS}

Comparisons have demonstrated that the WIND/MGBK suite of codes can qualitatively predict noise reduction trends measured between separate flow jets with and without chevrons on the core nozzle. Comparisons have also been shown that indicate that the CRAFT code, as described in Reference 1 , is likewise able to produce a mean flow solution suitable for subsequent noise predictions with MGBK for this realistic 3-dimensional nozzle geometry. Mean flow predictions were validated against PIV and pressure and temperature data, and noise predictions were validated against acoustic measurements recorded in the NASA Glenn Aeroacoustic Propulsion Lab.

This work is part of an ongoing assessment at NASA Glenn to determine the viability of the WIND/MGBK suite for use as a design tool for jet noise reduction concepts. Towards that end two issues must be continue to be addressed - accuracy and speed.

While the results shown here indicate that trends in noise reduction can be predicted for similar nozzles, discrepancies between the measured and predicted flow field and noise levels still exist. It is not known to what extent the two are related. New turbulence modeling and noise source modeling techniques must continue to be independently validated for a range of operating conditions and nozzle geometries.

Ways in which noise predictions can be obtained faster must address the most time consuming parts of the analysis, including grid generation. While convergence for the WIND solution could be further accelerated by using wall functions and moving the far field boundaries closer, there are consequences associated with these practices that must be considered when studying nozzles being redesigned for reducing noise. Trends in quiet nozzle concepts are more geometrically complicated, resulting in more complicated flows in the plume. For subsonic flows, pushing the far field boundaries in closer may result in unwanted boundary effects, particularly at low freestream flow conditions. Also, imposing the assumption of the law of the wall to calculate the boundary layer velocity layer profiles may not always be appropriate for these new nozzle concepts where the characteristics of the boundary layer flow are not always known a priori.

Answers to these and other questions can only be answered by additional parametric studies. The work 
presented here is part of that growing, publicly presented effort. The combination of the data being collected in the AAPL and the predictions done with WIND/MGBK serves as an excellent resource to gauge the progress being made in turbulent jet predictions and noise source modeling.

\section{REFERENCES}

1. Kenzakowski, D.C., J. Shipman, S.M. Dash, J. Bridges, and N. Saiyed, "Study of Three-Stream Laboratory Jets with Passive Mixing Enhancements for Noise Reduction," AIAA-20000219, 2000.

2. Bridges, J., "Measurements of Turbulent Flow Field in Separate Flow Nozzles With Enhanced Mixing Devices-Test Report," NASA/TM-2002211366, 2002.

3. Bridges, J. and M.P. Wernet, "Turbulence Measurements of Separate Flow Nozzles with Mixing Enhancement Features," NASA/TM2002-211592, 2002.
4. Wernet, M.P., "Fuzzy Logic Enhanced Digital PIV Processing Software," NASA/TM-1999-209274, 1999.

5. Bush, R.H., G.D. Power, and C.E. Towne, "WINDThe Production Flow Solver of the NPARC Alliance," AIAA-1998-0935, 1998.

6. Koch, L.D., J. Bridges, and A. Khavaran, "Flowfield Comparisons from Three Navier-Stokes Solvers for an Axisymmetric Separate Flow Jet," NASA/TM-2002-211350, 2002.

7. Ahuja, K.K., B.J. Testor, and H.K. Tanna, "The Free Jet as a Simulator of Forward Velocity Effects on Jet Noise," NASA CR-3056, 1979.

8. Khavaran, A., "Role of Anisotropy in Turbulent Mixing Noise," AIAA Journal, 37(7), July 1999, pp. 832-841.

9. Balsa, T.F., "The Far Field of High Frequency Convected Singularities in Sheared Flows," J. Fluid Mechanics, 74, 1976, pp. 193-208.

10. Wundrow, D.W. and A. Khavaran, "On the Applicability of High-Frequency Approximations to Lilley's Equation," NASA/CR-2003-212089, 2003. 


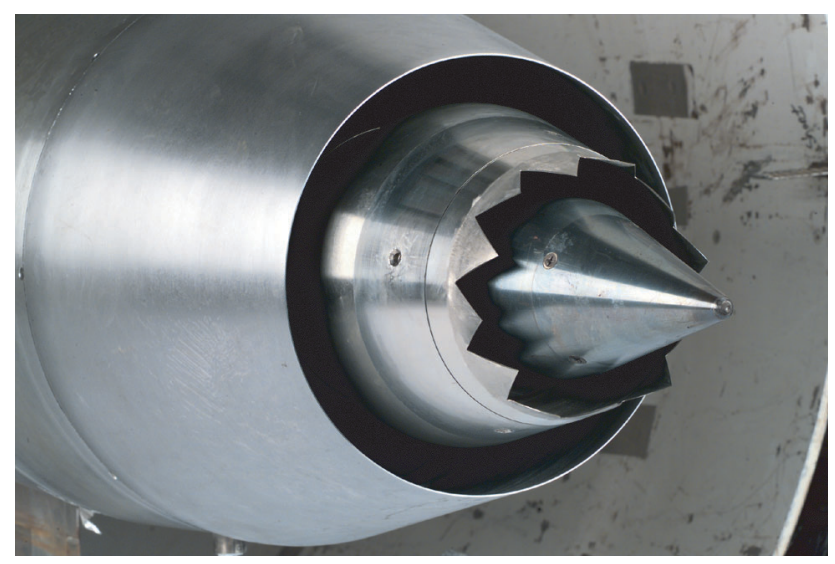

Figure 1.-Separate flow nozzle $3 A_{12} B$ hardware.

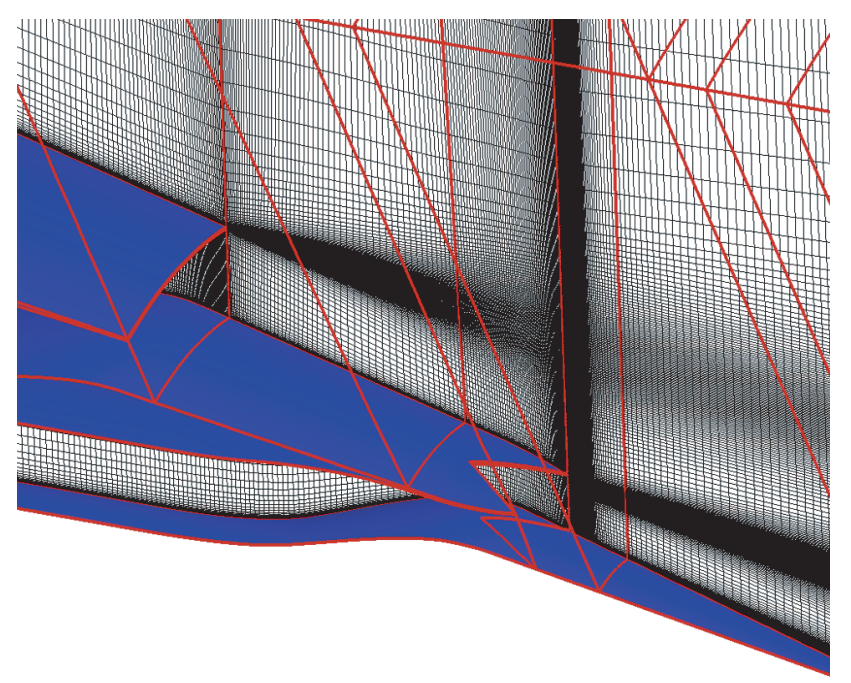

Figure 2.-Detail of computational grid for the WIND prediction.

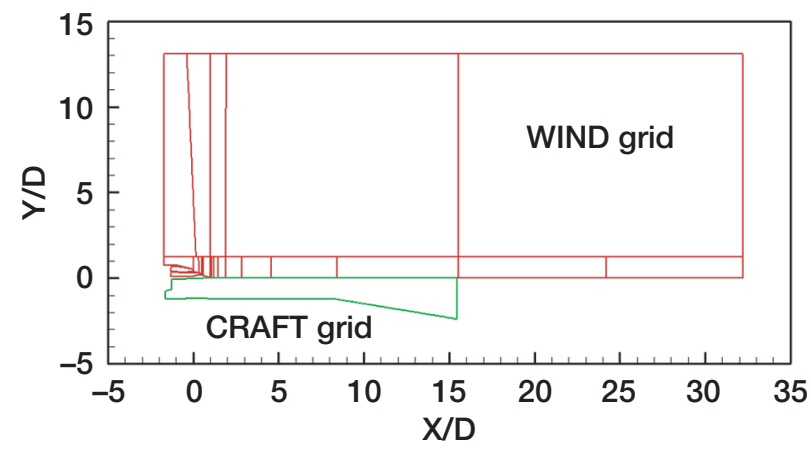

Figure 3.-Comparison of the external boundary placement for the WIND and CRAFT grids. 

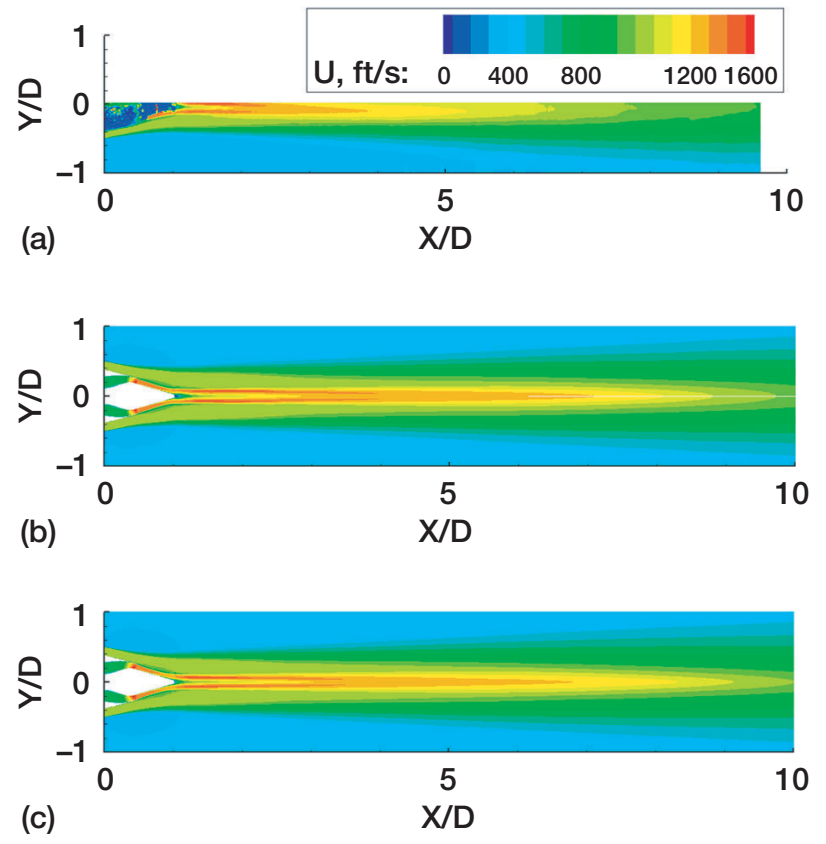

Figure 4.-Axial velocity distributions in the plane of the downward chevron for a) PIV data, b) CRAFT prediction, and c) WIND prediction.
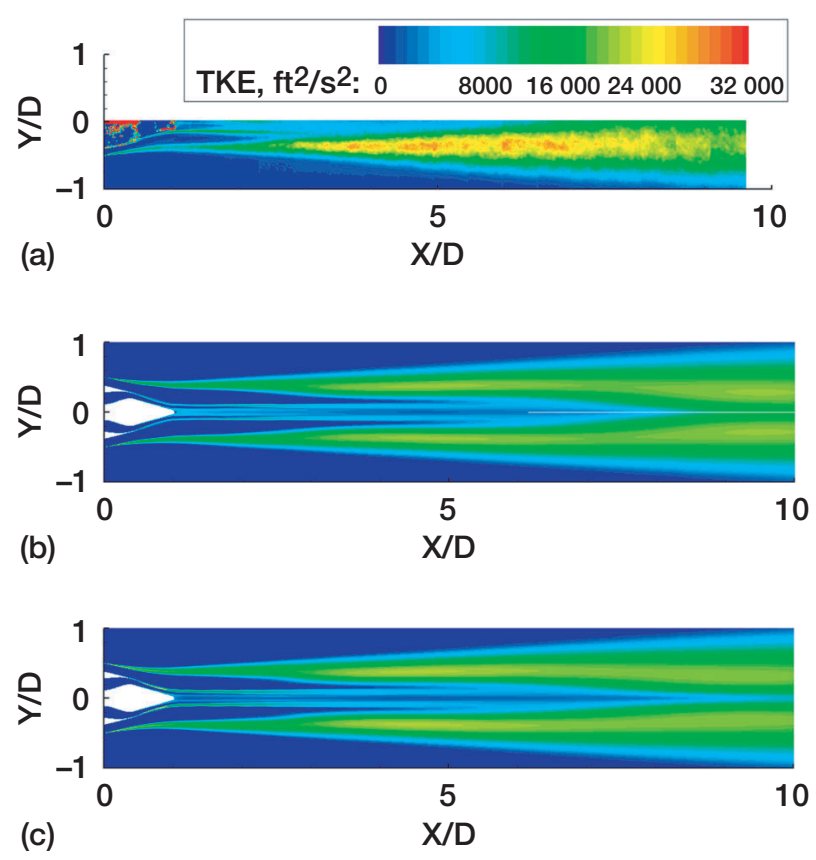

Figure 6.-Turbulence kinetic energy distributions in the plane of the downward chevron for a) PIV data, b) CRAFT prediction, and c) WIND prediction.
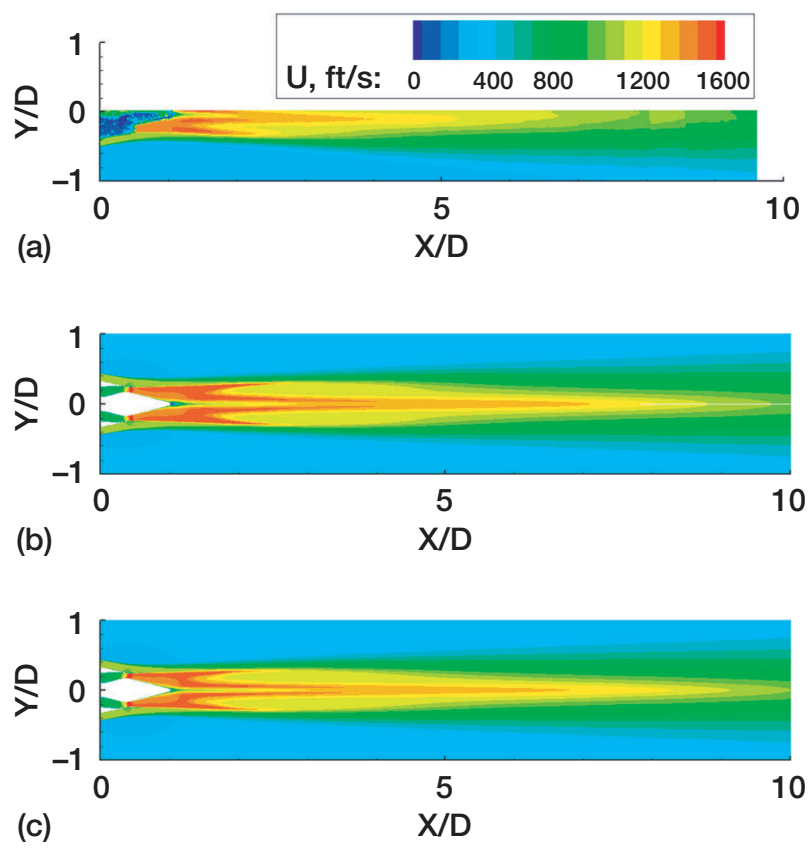

Figure 5.-Axial velocity distributions in the plane of the upward chevron for a) PIV data, b) CRAFT prediction, and c) WIND prediction.
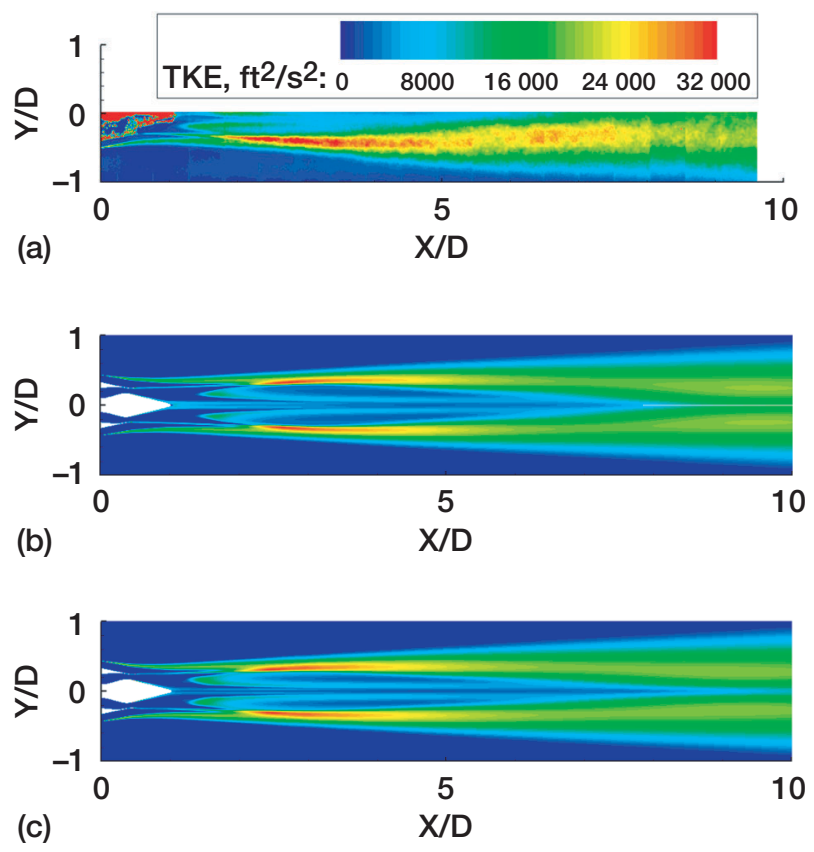

Figure 7.-Turbulence kinetic energy distributions in the plane of the upward chevron for a) PIV data, b) CRAFT prediction, and c) WIND prediction. 


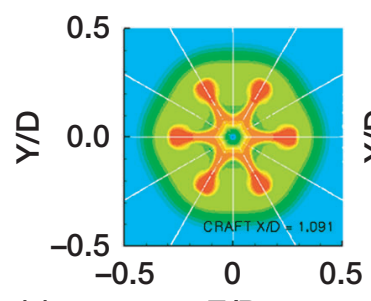

(a)

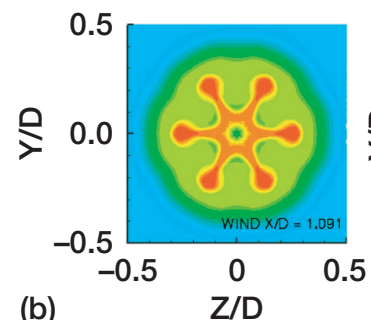

(b)
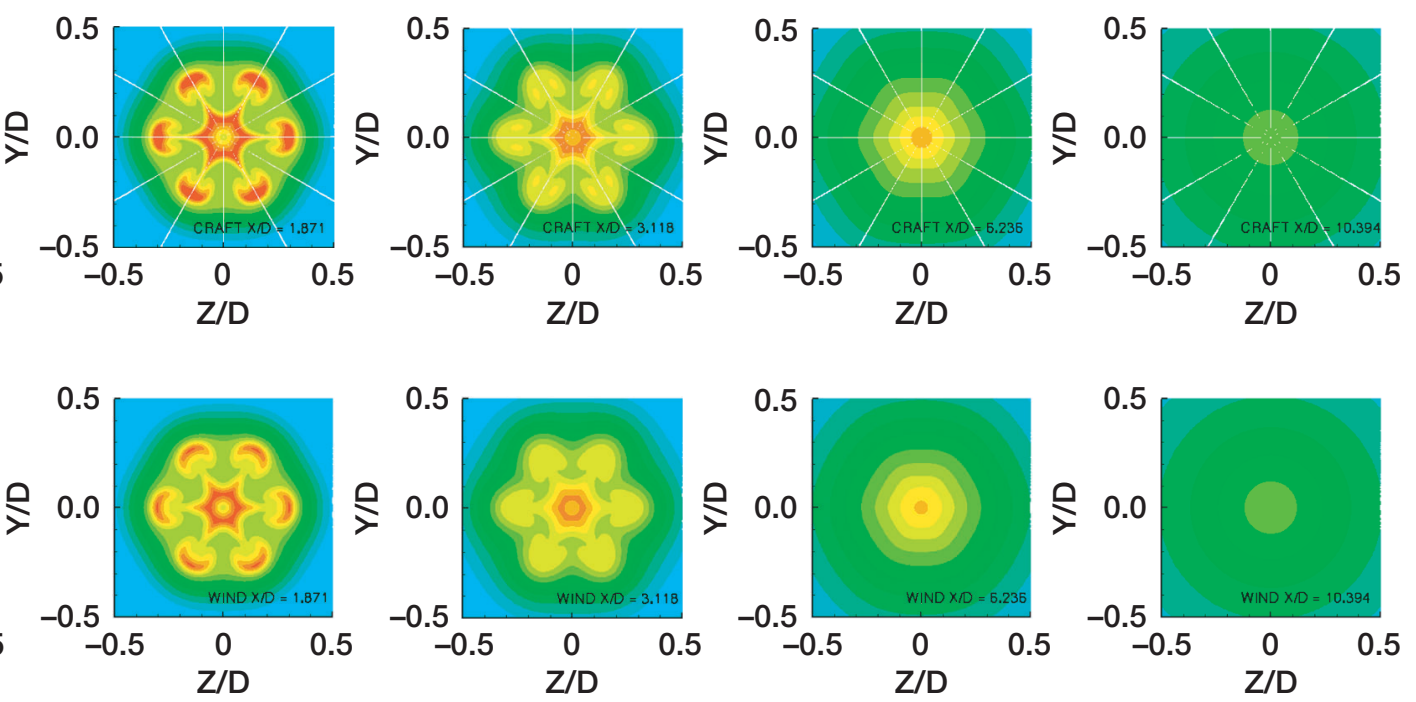

Figure 8.-Cross-sectional axial velocity distributions for a) CRAFT prediction, and b) WIND prediction.
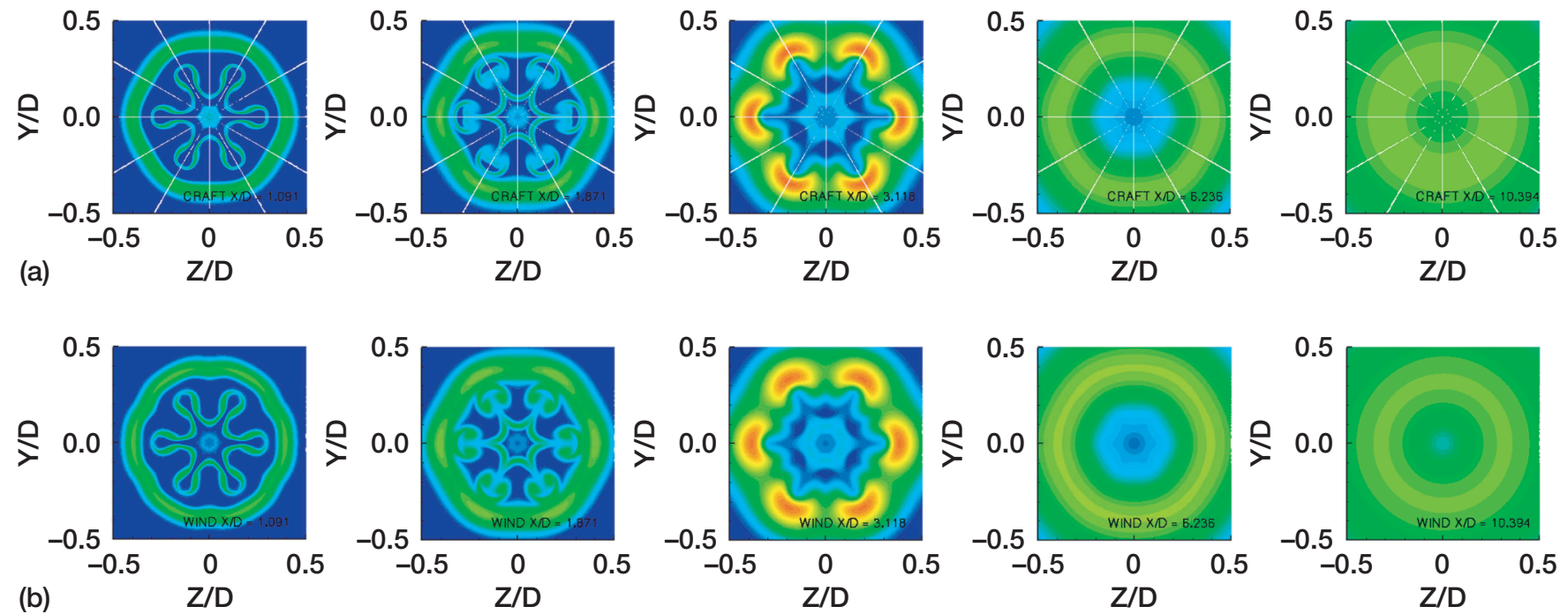

Figure 9.-Cross-sectional turbulence kinetic energy distributions for a) CRAFT prediction, and b) WIND prediction. 

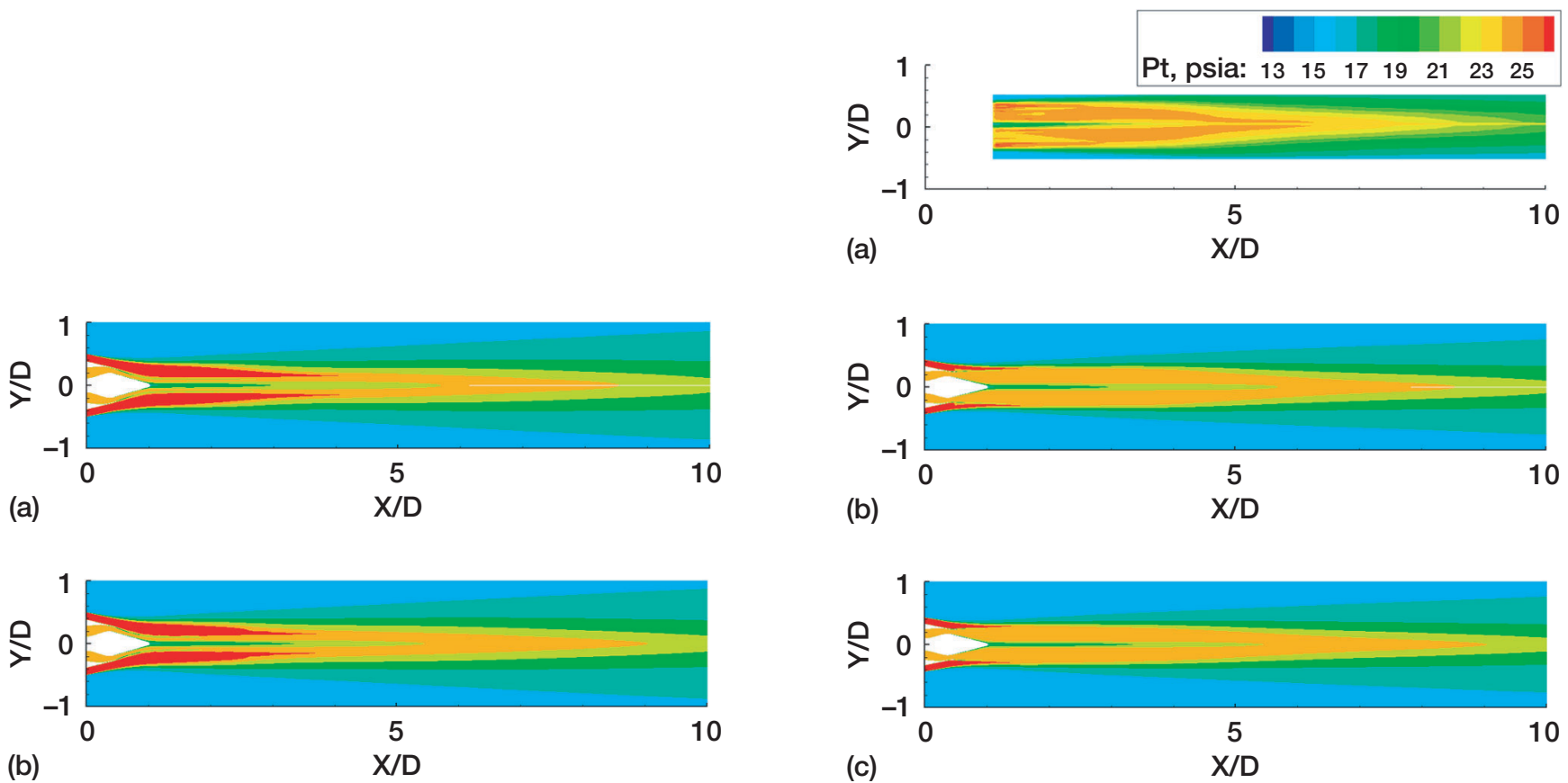

Figure 10.-Total pressure distributions in the plane of the downward chevron for a) CRAFT prediction, and b) WIND prediction.
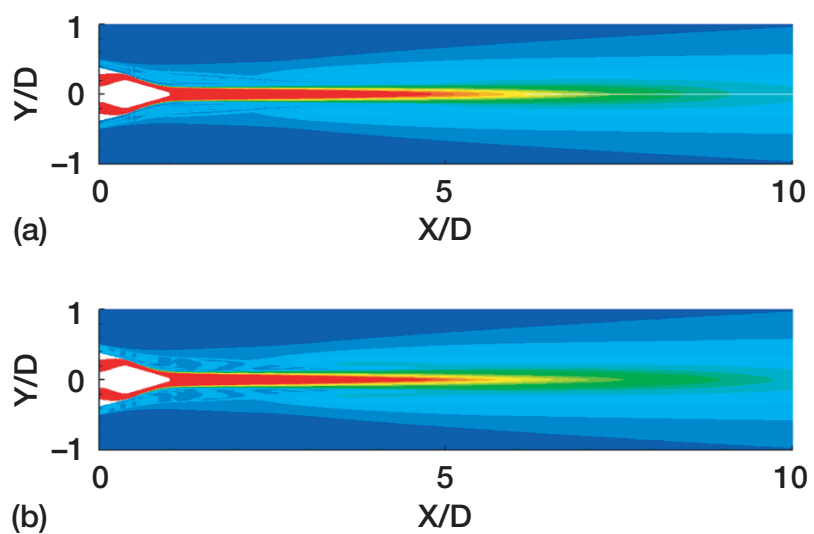

Figure 12.-Total temperature distributions in the plane of the downward chevron for a) CRAFT prediction, and b) WIND prediction.
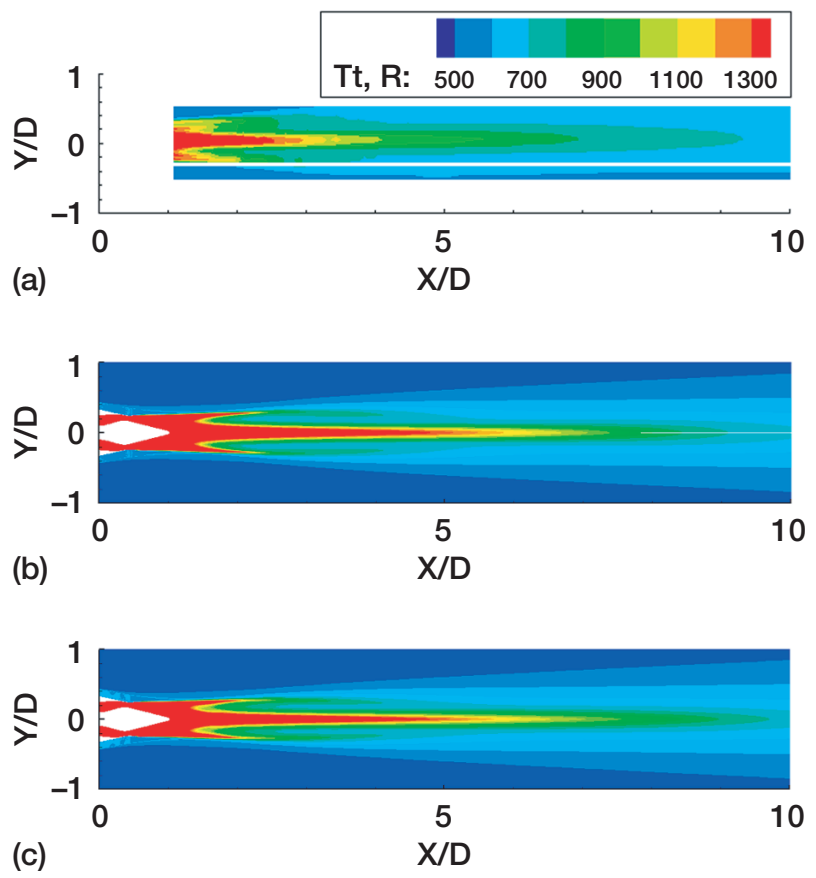

Figure 13.-Total temperature distributions in the plane of the upward chevron for a) $3 A_{12} B$ rake data, b) CRAFT prediction, and c) WIND prediction. 

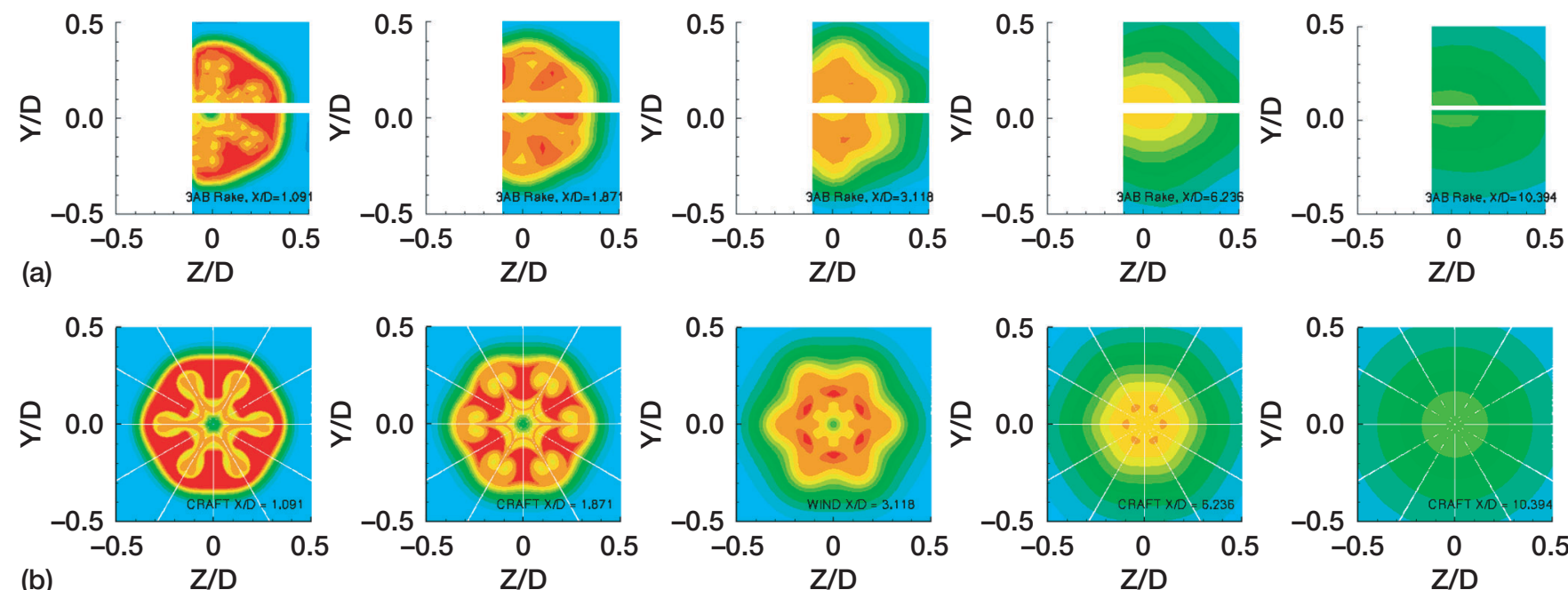

(b)
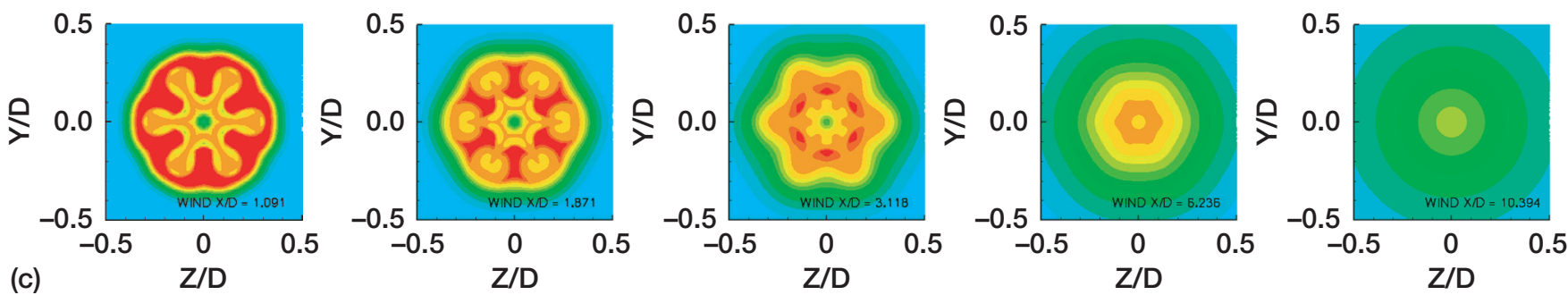

Figure 14.-Cross-sectional total pressure distributions for a) $3 \mathrm{~A}_{12} \mathrm{~B}$ rake data, b) CRAFT prediction, and c) WIND prediction.
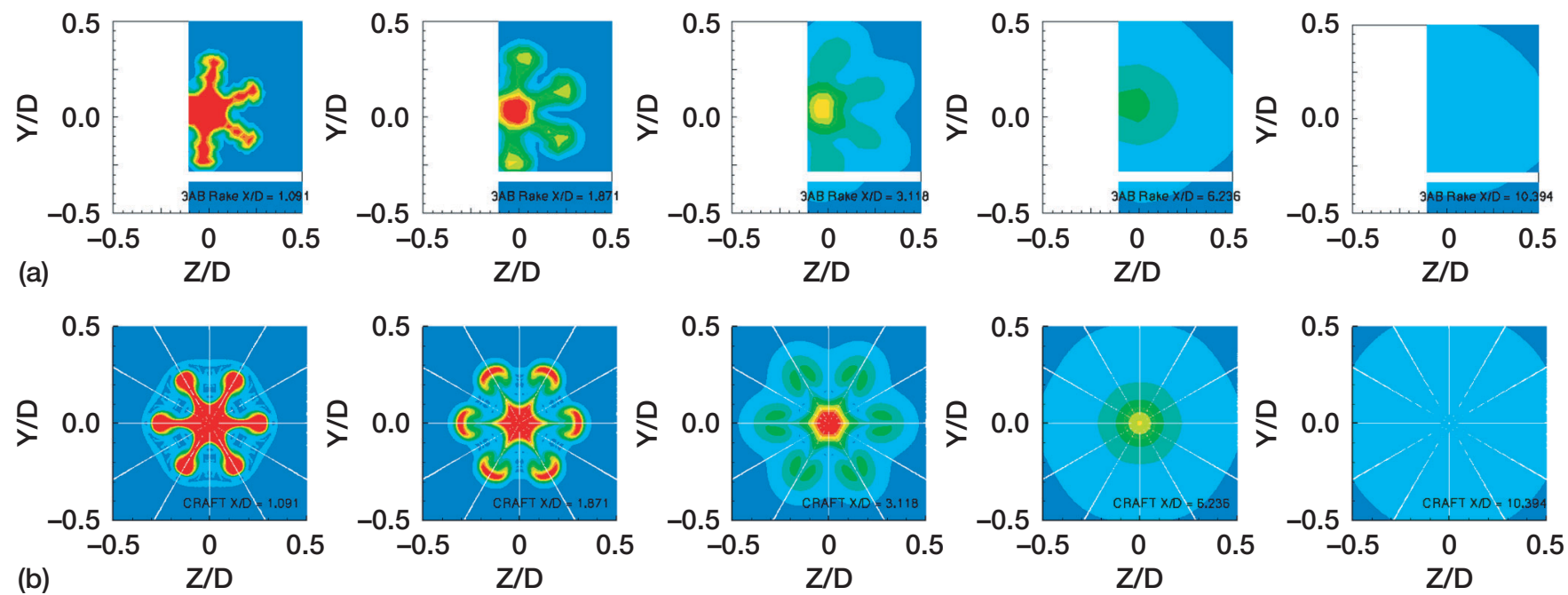

(b)
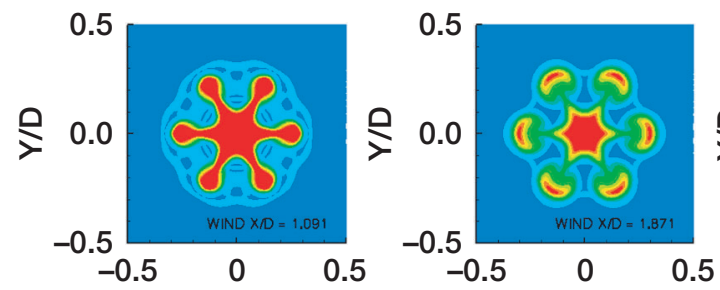

(c) Z/D
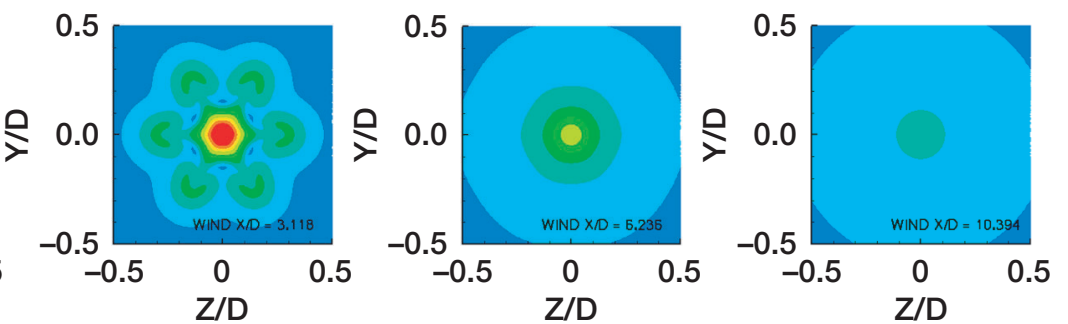

Figure 15.-Cross-sectional total temperature distributions for a) $3 \mathrm{~A}_{12} \mathrm{~B}$ rake data, b) CRAFT prediction, and c) WIND prediction. 


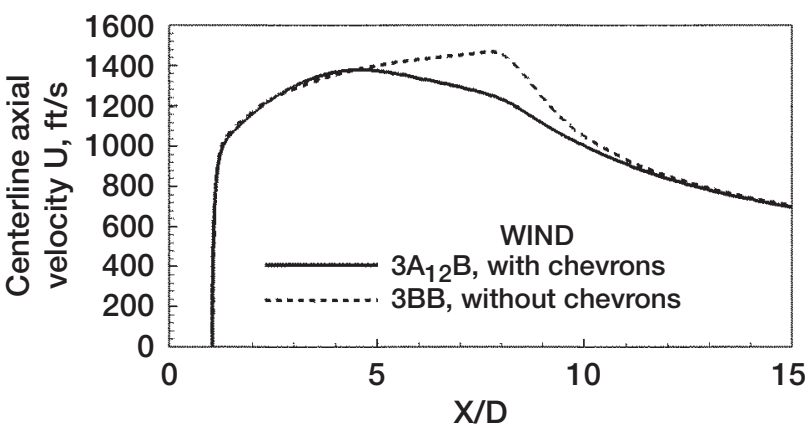

Figure 16.-Comparison of the centerline axial velocity distributions from the WIND code for the $3 A_{12} B$ nozzle with chevrons and the $3 B \mathrm{~B}$ nozzle without chevrons.
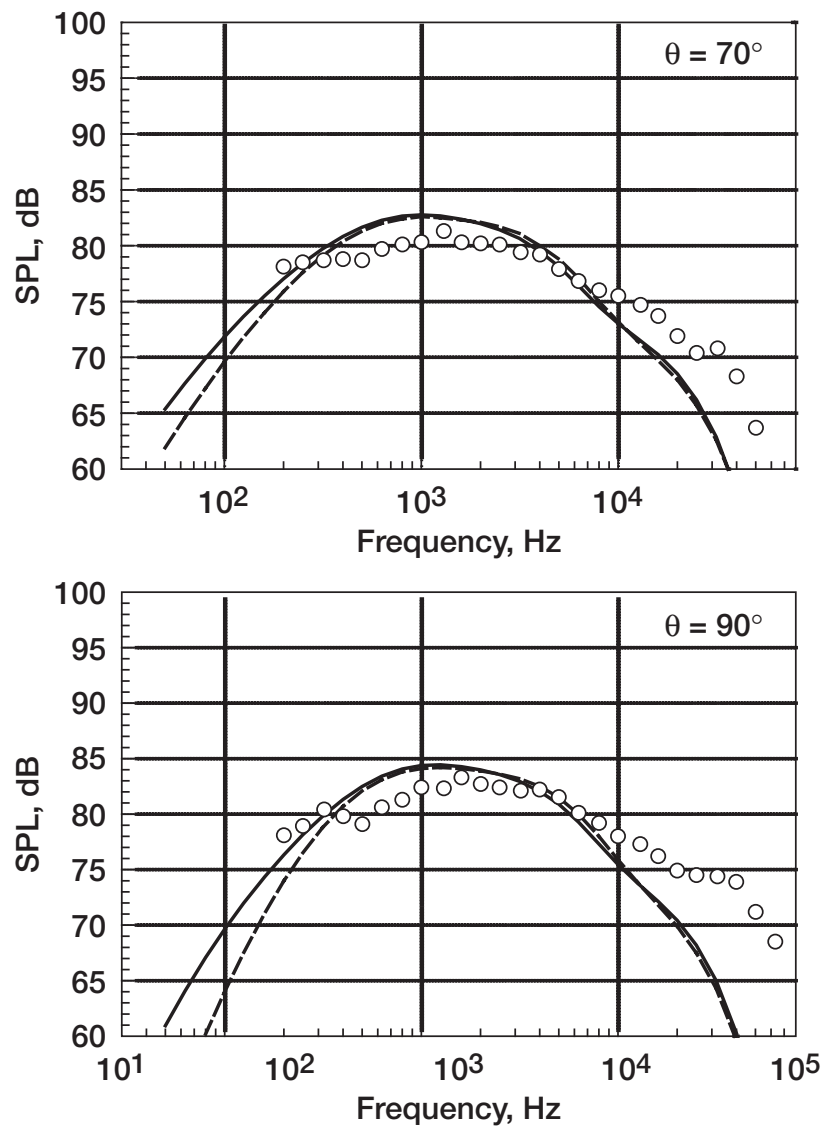

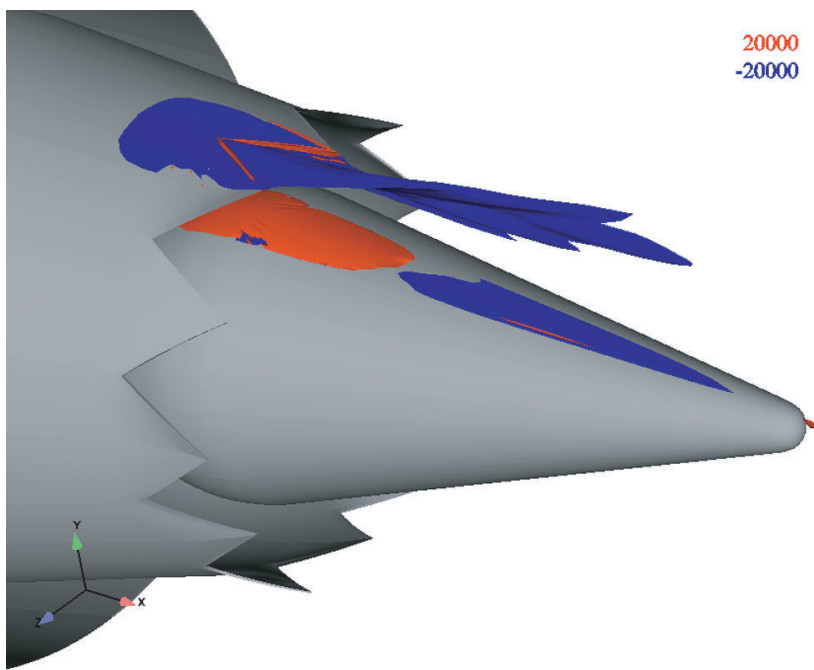

Figure 17.-Axial vorticity iso-surfaces near the chevrons for the $3 \mathrm{~A}_{12} \mathrm{~B}$ nozzle WIND prediction.
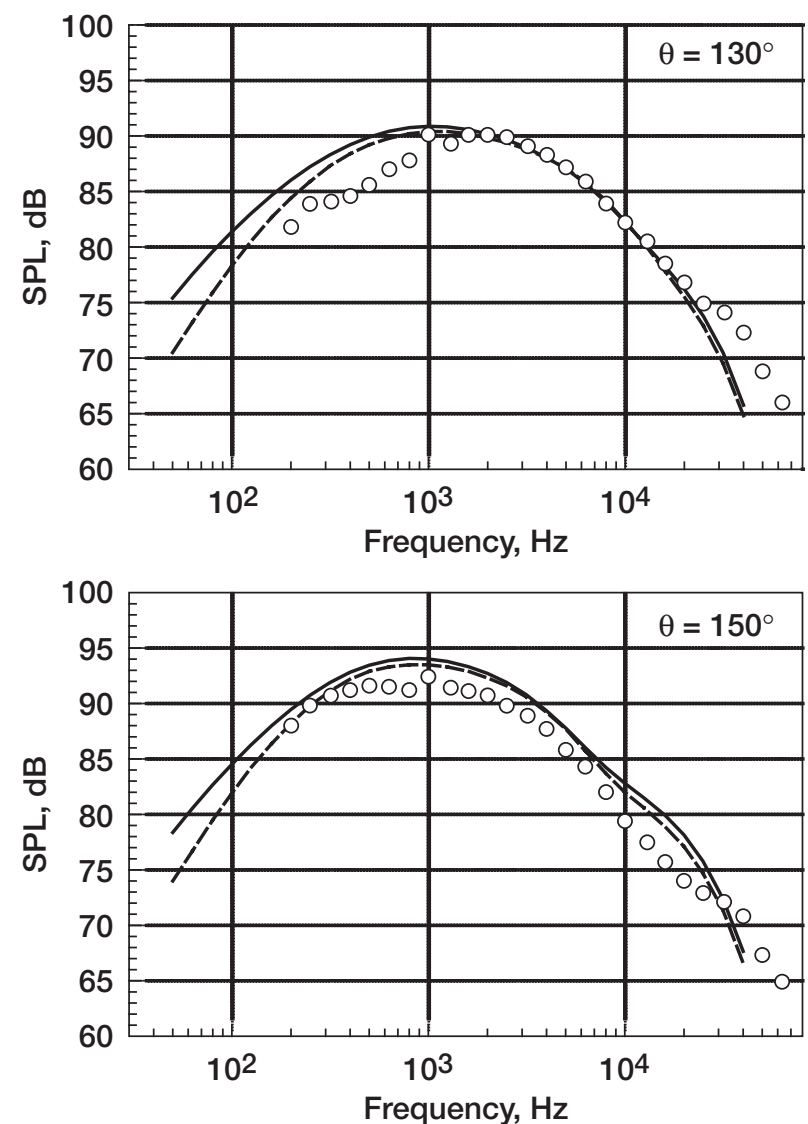

Figure 18.-Predicted noise spectra on arc $(R / D=62.6)$. Solid line, WIND input; dashed line, CRAFT input; symbol data. 


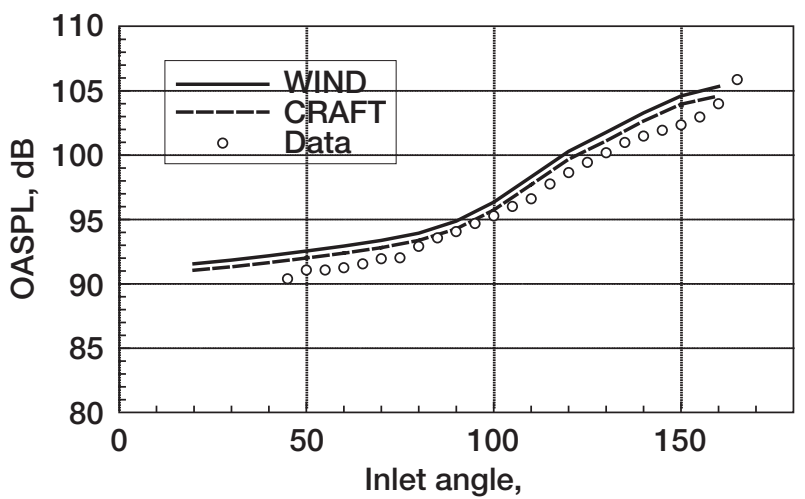

Figure 19.-Predicted overall sound pressure directivity and comparison with data.

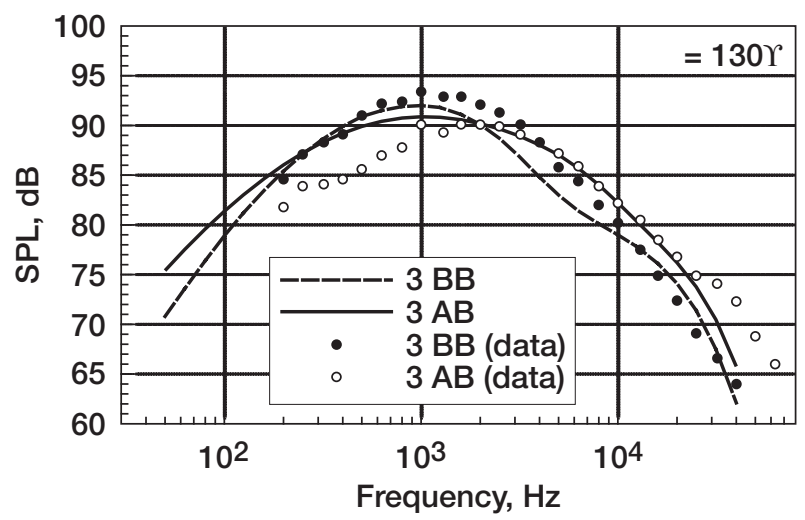

Figure 20.-Predicted spectra for base dual flow nozzle (3BB) and the chevron nozzle $\left(3 \mathrm{~A}_{12} \mathrm{~B}\right)$ and comparison with data. 


\begin{tabular}{|c|c|c|}
\hline \multicolumn{2}{|c|}{ REPORT DOCUMENTATION PAGE } & $\begin{array}{l}\text { Form Approved } \\
\text { OMB No. 0704-0188 }\end{array}$ \\
\hline \multicolumn{3}{|c|}{$\begin{array}{l}\text { Public reporting burden for this collection of information is estimated to average } 1 \text { hour per response, including the time for reviewing instructions, searching existing data sources, } \\
\text { gathering and maintaining the data needed, and completing and reviewing the collection of information. Send comments regarding this burden estimate or any other aspect of this } \\
\text { collection of information, including suggestions for reducing this burden, to Washington Headquarters Services, Directorate for Information Operations and Reports, } 1215 \text { Jefferson } \\
\text { Davis Highway, Suite 1204, Arlington, VA 22202-4302, and to the Office of Management and Budget, Paperwork Reduction Project (0704-0188), Washington, DC 20503. }\end{array}$} \\
\hline 1. AGENCY USE ONLY (Leave blank) & \begin{tabular}{|c|c|} 
2. REPORT DATE & 3. \\
February 2004 &
\end{tabular} & $\begin{array}{l}\text { D DATES COVERED } \\
\text { echnical Memorandum }\end{array}$ \\
\hline & Mean Flow and Noise Prediction for a Separate Flow Jet With Chevron Mixers & 5. FUNDING NUMBERS \\
\hline $\begin{array}{l}\text { 6. AUTHOR(S) } \\
\text { L. Danielle Koch, James Bri }\end{array}$ & s, and Abbas Khavaran & WBS-22-781-30-46 \\
\hline $\begin{array}{l}\text { 9. SPONSORING/MONITORING AGEI } \\
\text { National Aeronautics and Sp } \\
\text { Washington, DC 20546-00 }\end{array}$ & $\begin{array}{l}\text { NAME(S) AND ADDRESS(ES) } \\
\text { Administration }\end{array}$ & $\begin{array}{l}\text { 10. SPONSORING/MONITORING } \\
\text { AGENCY REPORT NUMBER } \\
\text { NASA TM-2004-212906 } \\
\text { AIAA-2004-0189 }\end{array}$ \\
\hline
\end{tabular}

Prepared for the 42nd Aerospace Sciences Meeting and Exhibit sponsored by the American Institute of Aeronautics and Astronautics, Reno, Nevada, January 5-8, 2004. L. Danielle Koch and James Bridges, NASA Glenn Research Center; and Abbas Khavaran, QSS Group, Inc., Cleveland, Ohio 44135. Responsible person, L. Danielle Koch, organization code 5940, 216-433-5656.

12a. DISTRIBUTION/AVAILABILITY STATEMENT 12b. DISTRIBUTION CODE

Unclassified - Unlimited

Subject Categories: 02, 34, and 71

Distribution: Nonstandard

Available electronically at http://gltrs.grc.nasa.gov

This publication is available from the NASA Center for AeroSpace Information, 301-621-0390.

13. ABSTRACT (Maximum 200 words)

Experimental and numerical results are presented here for a separate flow nozzle employing chevrons arranged in an alternating pattern on the core nozzle. Comparisons of these results demonstrate that the combination of he WIND/ MGBK suite of codes can predict the noise reduction trends measured between separate flow jets with and without chevrons on the core nozzle. Mean flow predictions were validated against Particle Image Velocimetry (PIV), pressure, and temperature data, and noise predictions were validated against acoustic measurements recorded in the NASA Glenn Aeroacoustic Propulsion Lab. Comparisons are also made to results from the CRAFT code. The work presented here is part of an on-going assessment of the WIND/MGBK suite for use in designing the next generation of quiet nozzles for turbofan engines.

14. SUBJECT TERMS 15. NUMBER OF PAGES

Navier-Stokes; Exhaust nozzle; Mixing; Turbulence; Aerodynamic noise 19

\begin{tabular}{|c|c|c|}
\hline $\begin{array}{c}\text { 17. SECURITY CLASSIFICATION } \\
\text { OF REPORT } \\
\text { Unclassified }\end{array}$ & $\begin{array}{c}\text { 18. SECURITY CLASSIFICATION } \\
\text { OF THIS PAGE } \\
\text { Unclassified }\end{array}$ & $\begin{array}{c}\text { 19. SECURITY CLASSIFICATION } \\
\text { OF ABSTRACT } \\
\text { Unclassified }\end{array}$ \\
\hline
\end{tabular}

NSN 7540-01-280-5500 